\title{
Simulation Design of Variable Frequency Speed Regulating System for Automobile Remanufactured Generator Test Bench Based on Matlab
}

\author{
Huilong Lv, Yiping Luo \\ College of Automotive, Shanghai University Of Engineering Science, Shanghai, China \\ Email:18817305023@163.com
}

How to cite this paper: Lv, H.L. and Luo, Y.P. (2018) Simulation Design of Variable Frequency Speed Regulating System for Automobile Remanufactured Generator Test Bench Based on Matlab. Open Access Library Journal, 5: e4628.

https://doi.org/10.4236/oalib.1104628

Received: April 27, 2018

Accepted: May 27, 2018

Published: May 30, 2018

Copyright ( 2018 by authors and Open Access Library Inc.

This work is licensed under the Creative Commons Attribution International License (CC BY 4.0).

http://creativecommons.org/licenses/by/4.0/

\begin{abstract}
There are many types of vehicle generators and their parameters are different. Therefore, the motor selected for the remanufacturing test bench should be suitable for most generators. Therefore, there is a certain requirement for the adjustment range of the motor speed. The AC-DC-AC frequency converter has a large frequency adjustment range, which can meet the motor speed control requirements. In this paper, the Simulink visual simulation tool Simulink modeling and simulation of AC-DC-AC inverter circuit, according to re-manufactured generator test to change the motor-related parameters, and the resulting waveform analysis.
\end{abstract}

\section{Subject Areas}

Automata

\section{Keywords}

Matlab, Test Bench, AC-DC-AC Inverter Circuit, Modeling, Simulation

\section{Introduction}

As a raw material for remanufacturing production, the generator failure mode is different. To ensure the quality of the generator, we need to test the performance and quality of the remanufactured generator. Therefore, we need to develop a test stand with high precision, high efficiency, and general-purpose performance to test the generator. On the other hand, the parameters of the generator are different, so the motor of the test stand needs to meet the detection requirements of 
most generators. In the motor selection, the choice of speed control system is very important. Frequency conversion speed regulation is the main trend of current motor speed control, which is mainly divided into AC-AC frequency conversion and AC-DC-AC frequency conversion [1]. The AC-DC-AC frequency converter has a larger range and can better meet the motor speed requirements. Simulink is a block diagram simulation platform, including the Power System module, which provides a physical graphical simulation model library. This article uses Simulink, a visual simulation tool in Matlab, to model the AC-DC-AC inverter circuit [2] [3].

\section{The Working Principle of the AC-DC-AC Inverter Circuit}

\subsection{Working Principle}

The schematic diagram of the AC-DC-AC variable frequency speed control system is shown in Figure 1. It consists of three modules: rectifier, filter, and inverter. The rectifying part is to rectify the external power frequency AC power supply, and provide the required DC power to the inverter circuit and the control circuit. The filtering section smoothes the output of the rectifier circuit to ensure that the inverter circuit and the control circuit obtain a higher quality DC power supply. The final inverter circuit converts the DC power output from the intermediate stage into an AC power source with adjustable frequency and voltage [4] [5].

\subsection{AC-DC-AC Inverter Parameter Determination}

We choose the frequency converter from the aspect of calculating power, and the following three formulas must be satisfied for continuously operating frequency converters.

(1) Meet the load output: $P_{C N} \geq P N / \eta$

(2) Meet the motor capacity: $P_{C N} \geq 3 k U_{e} I_{e} \times 10^{-3}$

(3) Meet the motor current: $I_{C N} \geq k I_{e}$

In the formula $P_{C N}$-Inverter capacity;

$P_{N}$ - Load required motor shaft output power;

$\eta$-Motor efficiency, usually 0.85 ;

$k$-Current waveform compensation coefficient, usually about $1.05 \sim 1.1$;

$U_{e}$ - Motor rated voltage;

$I_{e}-$ Motor rated current;

$I_{C N}$ - Inverter rated current.

Table 1 shows the parameters of the selected motor. The parameters of the corresponding inverter are determined according to the selected motor parameters as shown in Table 2.

\section{System Modeling}

\subsection{The Construction of the Model}

In the "untitled" model window, the corresponding components are found in the original Simulink library for connection according to the AC-DC-AC 


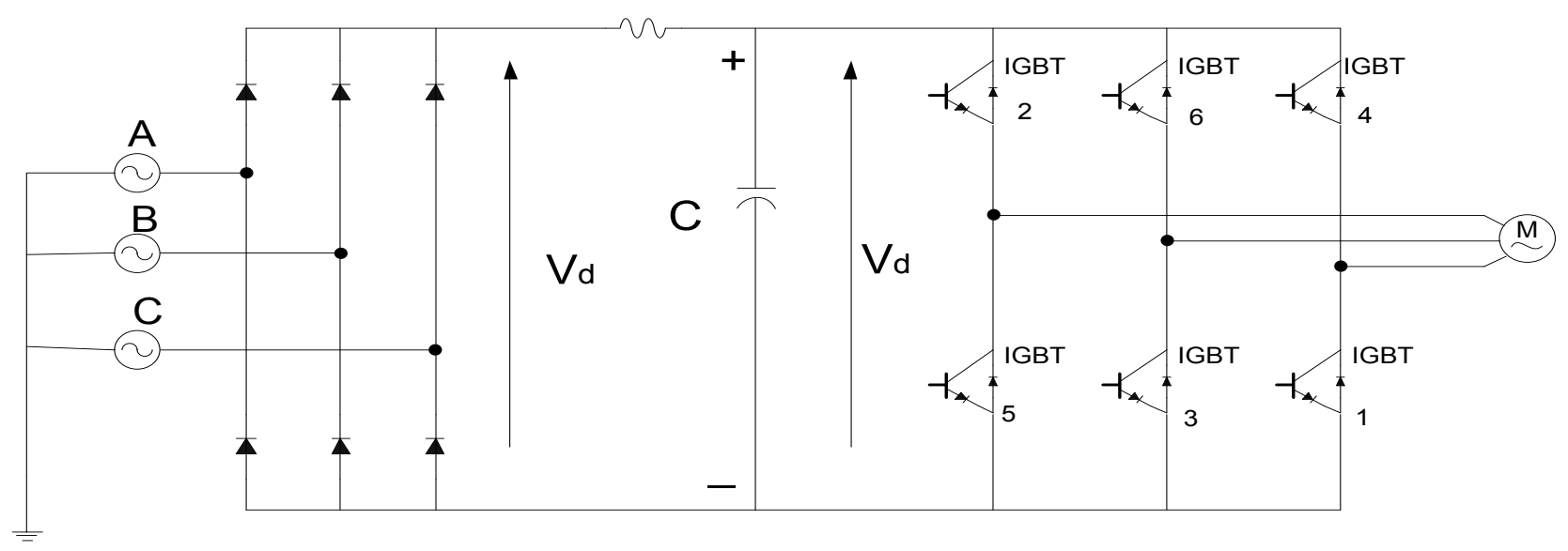

Figure 1. Schematic diagram of AC-DC frequency conversion speed regulation system.

Table 1. Three-phase asynchronous motor parameters.

\begin{tabular}{|c|c|c|c|c|c|}
\hline Model & Power $(\mathrm{Kw})$ & Rated current $I_{e}(\mathrm{~A})$ & Rated speed $n(r p m)$ & Efficiency $\quad \eta \%$ & Power Factor ( cos ) \\
\hline Y2-90L-2 & 2.2 & 4.9 & 2840 & 81 & 0.85 \\
\hline
\end{tabular}

Table 2. Inverter parameters.

Standard applies to motor output power $(\mathrm{Kw})$

Maximum applicable motor output power $(\mathrm{Kw})$

Output frequency range

Overload capacity

Phase number voltage frequency

Voltage, frequency allowable range of variation

$\begin{array}{ll}\text { Output rated capacity KVA } & 3.0 \\ \text { Output rated current A } & 10\end{array}$

$0.1 \mathrm{~Hz}-400 \mathrm{~Hz}$

150 ED Output current operation $20 \mathrm{~s}$

Single-phase/three-phase $200-240 \mathrm{~V}, 50 / 60 \mathrm{~Hz}$

Voltage: $\pm 10 \%$, frequency: $\pm 5 \%$

inverter circuit. The AC-DC-AC frequency conversion circuit consists of three modules: rectifier, inverter and filter. Therefore, the three-phase bridge-type uncontrollable rectifier circuit, three-phase voltage-type inverter circuit and the filter circuit were first modeled separately.

The parameters of the asynchronous motor module in the inverter circuit are shown in Table 3.

Finally, in the simulation/parameter window, select the ode23tb algorithm, the relative error is set to $1 \mathrm{e}-3$, and the stop time is set to $0.1 \mathrm{~s}$. The circuit simulation diagram obtained by the rectification, inversion, and filtering of the three modules is shown in Figure 2.

\subsection{Simulation Results and Analysis}

We set the power frequency to $60 \mathrm{~Hz}$ and $100 \mathrm{~Hz}$, respectively.

When the output power frequency is $60 \mathrm{~Hz}$, the resulting voltage simulation results are as follows

Through the analysis of the simulation results of the AC-DC-AC variable-frequency speed control system of Figure 3, the three-phase alternating 
Table 3. Asynchronous motor module parameters.

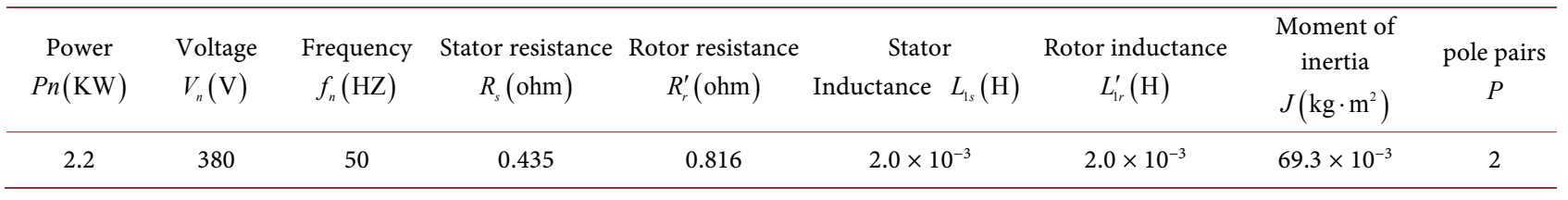

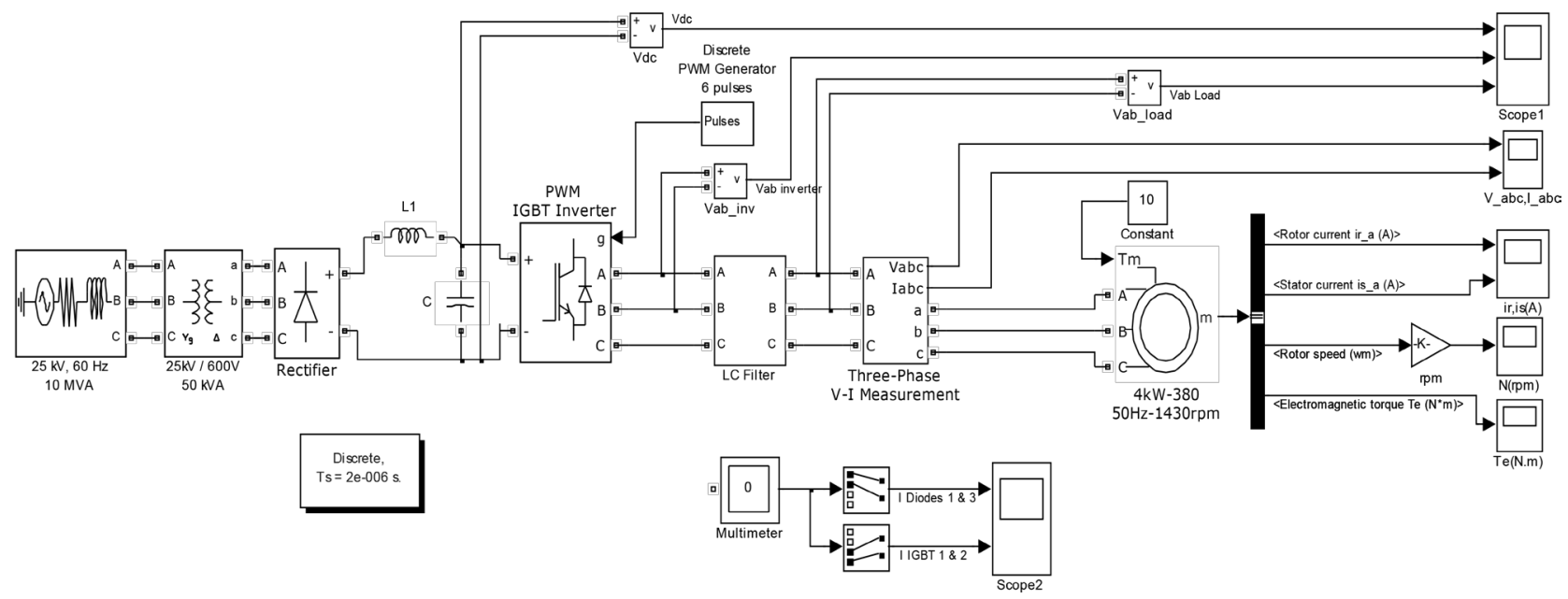

Figure 2. AC-DC-AC frequency conversion circuit simulation model.

current becomes a constant voltage DC voltage source after rectification, and the voltage waveform basically tends to a constant straight line. The wave after the inversion section is a square wave with adjustable pulse width. After feedback and LC filtering, it becomes a variable-frequency sine wave.

As we can see from Figure 4 and Figure 7, after the frequency of the output voltage increases, the rotational speed of the load motor rises slowly, and the speed and torque vibration amplitude of the open phase is small, and the smooth speed decreases, and the electromagnetic torque vibration decreases.

After filtering and frequency conversion of the three-phase voltage (Figure 5 and Figure 8) and current (Figure 6 and Figure 9), you can see the output frequency from $60 \mathrm{~Hz}$ to $100 \mathrm{~Hz}$, the voltage and current speed up, but the impact on the flat voltage is not large, and the current turn-on phase at $60 \mathrm{~Hz}$ when the vibration amplitude is relatively large, to After $0.25 \mathrm{~s}$, it tends to decrease gently, but the frequency is $100 \mathrm{~Hz}$, which is relatively gentle, but the copy is relatively large, which is not conducive to the work of the motor.

\section{Conclusion}

Through the comprehension and analysis of each part of the AC-DC-AC variable frequency speed control system, simulation experiments and research, based on the Matlab/Simulink simulation tool, the simulation model of the three-phase AC-DC frequency conversion speed control system was completed. Through the analysis of the operating results, we understand the basic working principle, characteristics and basic functions of the system, and basically realize the 
Vdc

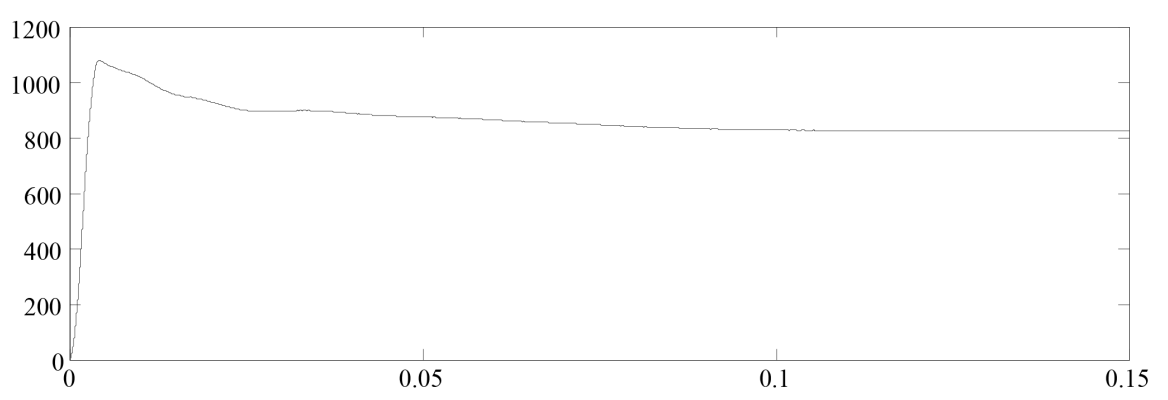

(a)

Vab inverter

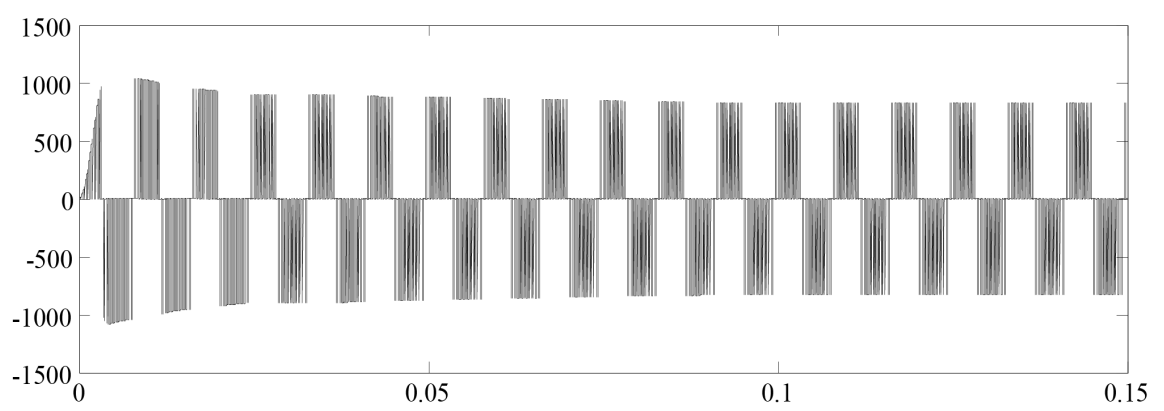

(b)

Vab Load

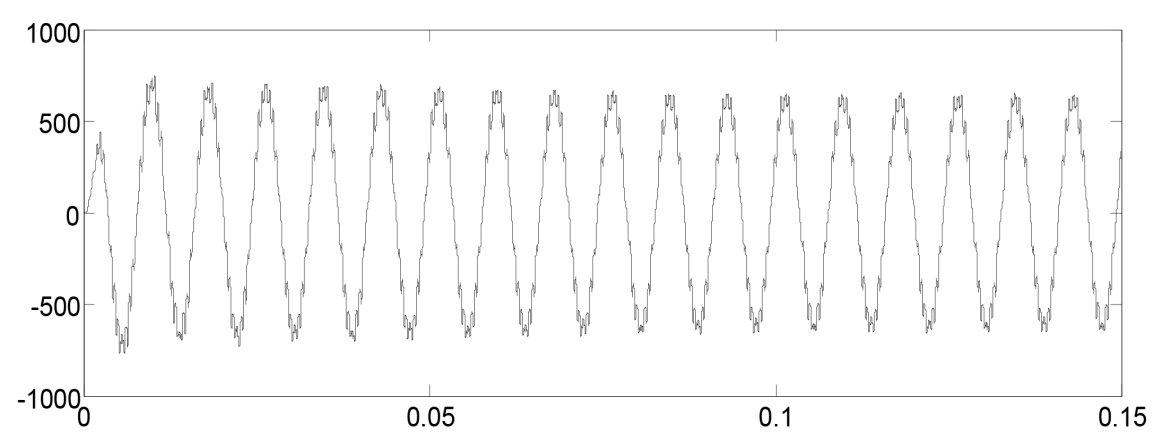

(c)

Figure 3. $(f=60 \mathrm{~Hz})$ AC-DC-AC frequency control voltage simulation waveform.

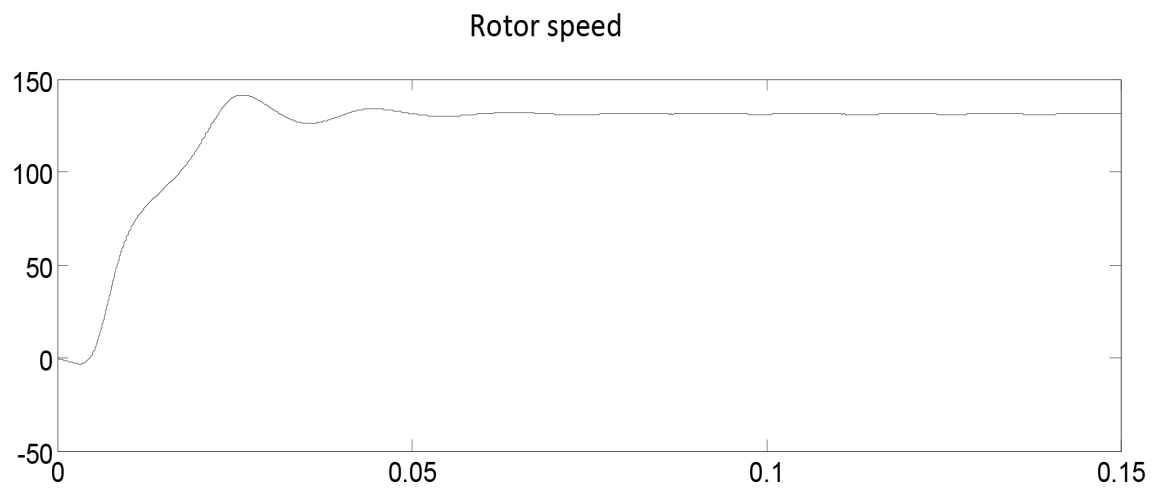

Figure 4. ( $f=60 \mathrm{~Hz})$ AC-DC-AC frequency motor speed waveform. 


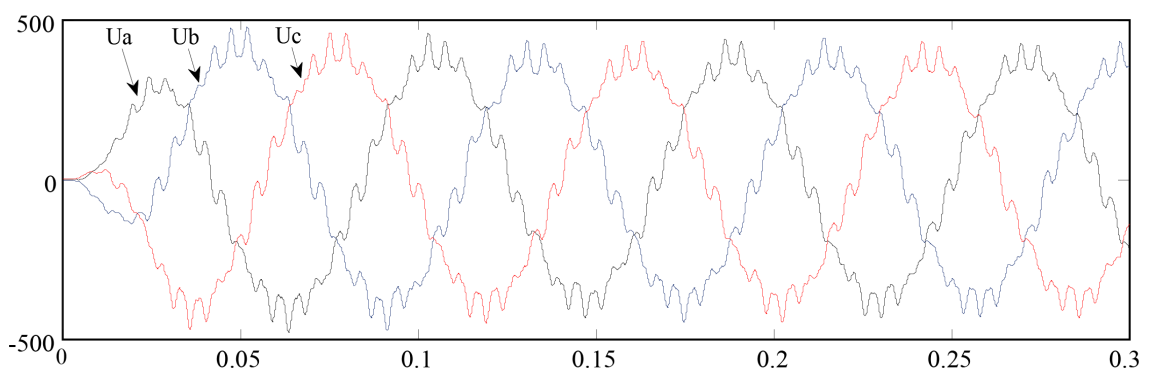

Figure 5. $(f=60 \mathrm{~Hz})$ Three-phase voltage simulation waveforms of AC-DC-AC variable speed.

labc

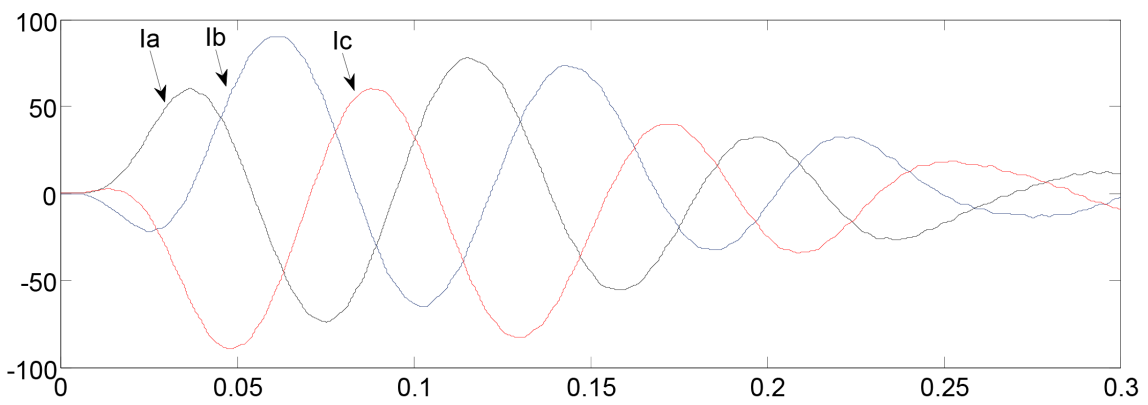

Figure 6. $(f=60 \mathrm{~Hz})$ AC-DC-AC variable speed three-phase current simulation waveform.

Rotor speed

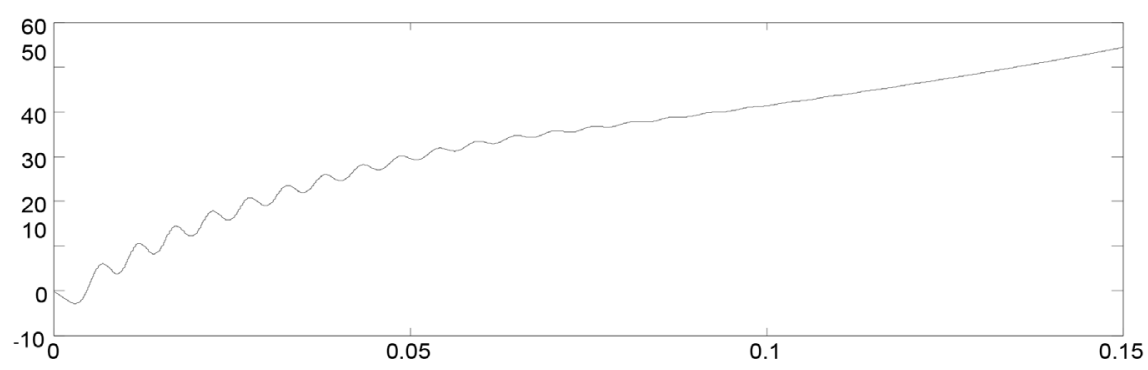

Figure 7. $(f=100 \mathrm{~Hz})$ AC-DC-AC frequency motor speed waveform.

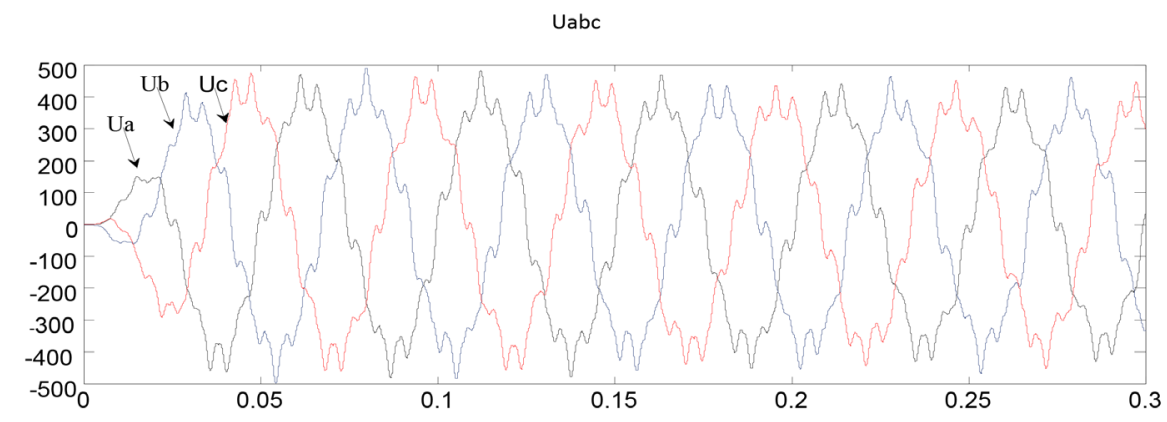

Figure 8. $(f=100 \mathrm{~Hz})$ Three-phase voltage simulation waveforms of AC-DC-AC variable frequency speed regulation. 
labc

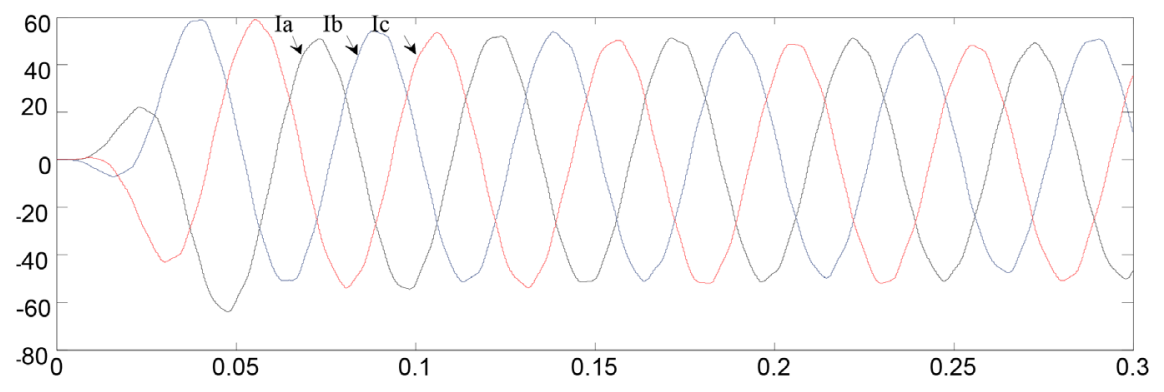

Figure 9. $(f=100 \mathrm{~Hz})$ AC-DC-AC frequency control three-phase current simulation waveform.

purpose of frequency conversion speed regulation, which can meet the demand for re-manufactured generator test-bed motor speed control.

\section{References}

[1] Zhang, J.M. (2010) Research and Development of Remanufacturing Test Bench for Automobile Used Transmission. Zhejiang University of Technology, Hangzhou.

[2] Han, X.D. and Li, M. (2012) Power Electronics Technology. Beijing Institute of Technology Press, Beijing.

[3] Su, C.Q. and Qing, M. (2017) Design and Simulation of Step-Down Chopper Circuit Based on MATLAB. Automated Application, No. 3, 43-45.

[4] Wei, R. (2007) Research on Simulation of AC-DC-AC Variable Frequency Speed Control System. Zhengzhou University, Zhengzhou.

[5] Zhou, Y.S. (2003) AC-DC Speed Control System and MATLAB Simulation. China Electric Power Press, Beijing. 